\title{
УДК 314.42
}

\author{
А. В. Кашепов \\ Московский педагогический государственный университет, Москва, \\ e-mail: avkash@list.ru
}

\section{ИЗБЫТОЧНАЯ СМЕРТНОСТЬ НАСЕЛЕНИЯ В 2020-2021 ГГ.}

Ключевые слова: пандемия коронавируса, общая смертность, избыточная смертность, мультипликатор смертности, факторы негативных демографических явлений.

Предлагаемая статья основывается на методологии детерминации воспроизводства населения и смертности в первую социально-экономическими факторами. Данная статья начинает серию работ, которые будут посвящены изучению факторов общей и избыточной смертности населения в 20202021 годах в странах мира и РФ. В статье предлагается методика анализа избыточной смертности населения в период пандемии COVID-19, названная автором «ковидным мультипликатором смертности $(\mathrm{CMM}) »$. В основе данной методики лежит гипотеза о том, что коронавирус не только непосредственно является причиной смерти людей, но и вызывает в обществе цепную реакцию преждевременных смертей, вызванных перегрузкой инфраструктуры здравоохранения, ограниченностью финансовых, кадровых, лекарственных и медико-технологических ресурсов. Целью статьи является обзор имеющихся публикаций по проблематике избыточной смертности от пандемии коронавируса и обоснование возможностей использования в этом направлении исследований индекса мультипликатора СММ. Произведен обзор научной литературы, оперативных данных и статистических публикаций по вопросам смертности от пандемии COVID-19 и ее медицинских, социальных, экономических последствий Представлены сделанные автором расчеты избыточной смертности за период с начала пандемии по март 2021 года. Предложены основные направления использования методологии СММ.

\section{A. V. Kashepov}

Moscow state pedagogical University, Moscow, e-mail: avkash@list.ru

\section{EXCESS MORTALITY OF THE POPULATION IN 2020-2021}

Keywords: coronavirus pandemic, total mortality, excess mortality, mortality multiplier, factors of negative demographic phenomena.

The proposed article is based on the methodology of determining population reproduction and mortality primarily by socio-economic factors. This article begins a series of papers that will be devoted to the study of the factors of total and excess mortality in 2020-2021 in the countries of the world and the Russian Federation. The article proposes a method for analyzing excess mortality in the population during the COVID-19 pandemic, called by the author "covid mortality multiplier (CMM)". This methodology is based on the hypothesis that the coronavirus is not only a direct cause of human death, but also causes a chain reaction of premature deaths in society caused by the overload of the health infrastructure, limited financial, human, medical and technological resources. The purpose of the article is to review the available publications on the problem of excess mortality from the coronavirus pandemic and to justify the possibilities of using the SMM multiplier index in this area of research. A review of the scientific literature, operational data and statistical publications on the issues of mortality from the COVID-19 pandemic and its medical, social, and economic consequences is made. The calculations of excess mortality made by the author for the period from the beginning of the pandemic to March 2021 are presented. The main directions of using the CMM methodology are proposed.

\section{Введение}

Автор данной статьи, признавая «демографический переход» как общую базу современных демографических теорий, а «демографический кризис», как наиболее адекватную систему объяснений того, что происходило в России в 1990-е годы, разрабатывает концепцию экономической детерминации демографических процессов, основной идеей которой является тезис о существенном влиянии ВВП, бюджетных расходов, доходов домашних хозяйств, уров- ней бедности и безработицы и других экономических процессов и показателей на воспроизводство населения, а также обратного влияния динамики и структуры населения на экономику [1;2].

По состоянию на 1 мая 2021 года, по данным Университета Дж. Хопкинса (США) общемировая численность официально учтенных зараженных новым коронавирусом составила 152 млн человек, число погибших 3,2 млн человек [4] По отношению к общему числу умерших 
в мире в 2019 году - 58 млн чел. [5], последнему из опубликованных ООН, глобальная смертность от COVID-19 в 2020 г. составила $3,1 \%$ (1,8 млн чел.). В РФ, согласно сопоставимым данным международной статистики, было 4,8 млн чел. зараженных и 109 тыс. чел. погибших.

\section{Проблема избыточной смертности в мире}

Часть прироста смертности была вызвана непосредственно новым коронавирусом. «Вклад» коронавируса в увеличение общей смертности варьирует по странам, как в результате различий в эффективности систем здравоохранения, так и стандартов разграничения причин смерти. Стрессы, вызванные как массовой заболеваемостью коронавирусом, так и введенными ограничениями на передвижение, работу, обязанностью использовать СИЗ и т.д. также повлияли на рост общей смертности. На рост общей смертности, превышающей непосредственную смертность от коронавируса, еще в середине 2020 года обращали внимание А. Ракша [6], Е.М. Щербакова [7] и другие демографы. В странах - акцепторах миграции (принимающих миграционные потоки) сократилось, или стало отрицательным, сальдо внешней миграции. Все это в комплексе вызвало в некоторых странах сокращение численности населения. По данным Росстата, численность постоянного населения РФ на 1 января 2020 года составляла 146748,6 тыс. чел., а на 1 января 2021 года 146238,2 тыс. чел., таким образом сокращение за год достигло 519,4 тыс. чел., против 32,1 тыс. чел. в 2019 г. [8].

Мы называем происходящее увеличение общей смертностью «избыточной смертностью», «дополнительной смертностью», «сверхсмертностью». В мировой литературе наиболее распространен термин «избыточная смертность» («excess mortality»). Новизна нашей методологии состоит в том, что мы предлагаем рассчитывать и использовать в анализе ситуации «мультипликатор избыточной смертности» по формуле:

$$
\mathrm{CMM}=\frac{\mathrm{M}_{\mathrm{i}}-\mathrm{M}_{\mathrm{b}}}{\mathrm{M}_{\mathrm{c}}}=\frac{\Delta \mathrm{M}_{\mathrm{g}}}{\mathrm{M}_{\mathrm{c}}},
$$

где CMM - covid mortality multiplier (ковидный мультипликатор смертности),

$\mathrm{M}_{\mathrm{i}}$ - число умерших от всех причин в исследуемом периоде времени,
$\mathrm{M}_{\mathrm{b}}$ - число умерших от всех причин в аналогичный период прошлого года (или «нормального» года, предшествующего пандемии),

$\mathrm{M}_{\mathrm{c}}$ - число умерших от COVID-19 в исследуемом периоде времени,

$\Delta \mathrm{M}_{\mathrm{g}}=\mathrm{M}_{\mathrm{i}}-\mathrm{M}_{\mathrm{b}}$ - динамика общего числа умерших (эксцесс общей смертности).

Необходимо подчеркнуть, что СММ это не просто индекс, а методологическая концепция анализа избыточной (дополнительной) смертности, которая базируется на представлении о том, что пандемия COVID-19 запускает процесс (реакцию) размножения негативных событий в обществе, в том числе дополнительных заболеваний и смертей, непосредственно не вызванных коронавирусом.

Размножение (мультипликация) случаев смертности вообще, и избыточная (дополнительная) смертность в частности, сильно варьируют по странам мира и регионам. Главной причиной дифференциации СММ по странам мира и регионам внутри стран является разная степень готовности национальных систем здравоохранения к подобным бедствиям. Но необходимо оценивать и более широкую категорию - уровень общественной готовности. Способность государств принимать и гарантированно исполнять ограничительные меры помогла многим из них успешно справиться с основными волнами пандемии. Различия национальных стандартов кодирования и учета заболеваний и причин смерти, которые не всегда полностью соответствуют рекомендациям BO3, также влияют на межгосударственные различия. По поводу готовности к событиям 2020 года национальных систем здравоохранения в странах мира в других публикациях мы уже высказывали мнение, что «реформы» и «оптимизация» здравоохранения в некоторых странах, в том числе в РФ, сводившиеся к сокращению численности больничных коек, врачей, медицинского персонала и экономии, недостаточному росту бюджетных расходов на здравоохранение, ослабляют резистентность общества к пандемии [3]. В странах, где наиболее активно проводились либеральные «реформы здравоохранения», в 2020-2021 годах пришлось потратить в десятки раз больше финансовых ресурсов на противодействие пандемии, и ликвидацию ее экономических последствий, чем было сэкономлено в предшествующие десятилетия в результате «реформ». 
В США опубликован общий прирост населения за 2020 год, который составил 3,1 млн чел. $(+0,9 \%)$ и общий коэффициент смертности $(\mathrm{OKC})-10$ человек на тысячу (промилле). Указывается, что прирост населения был самым низким, а ОКС самым высоким за несколько последних десятилетий. Необходимые для наших расчетов данные об общем числе умерших были представлены USA Bureau of the Census как предварительные на 15 декабря 2020 года, с указанием, что окончательные данные должны быть опубликованы в увязке с результатами переписи населения 2020 года - во второй половине 2021 года. Таким образом, официально зарегистрированное число умерших от COVID-19 в США на конец 2020 года составляло 352,5 тыс. чел, а прирост общего числа умерших 334 тыс. чел. [9]. Таким образом по США за 2020 год предварительная оценка $\mathrm{CMM}=0,96$, что означает, что государство и система здравоохранения справились с беспрецедентным ударом коронавируса (количество зараженных в этой стране в 2020 году намного превышало показатели других стран мира) и рост общей смертности был купирован ее сокращением от других причин (других категорий заболеваний). Тем не менее, американские эксперты используют термины «избыточной смертности» и «недоучета смертности от коронавируса», и продолжают анализировать ситуацию как по населению в целом, так и по наиболее уязвимым группам населения. Как писала в феврале 2021 года В. Удалова, старший экономист и руководитель программы улучшения данных о здоровье (EHealth) USA Bureau of the Census, «измерение как прямого, так и косвенного воздействия на смертность рисует более полную картину разрушений, вызванных продолжающейся пандемией COVID-19. Избыточная смертность от всех причин рассчитывается как разница между ожидаемой (основанной на исторических тенденциях) и наблюдаемой смертностью в течение данного периода. Недавние исследования показывают, что избыточная смертность от всех причин составляла 2,4 на 10000 человек в Соединенных Штатах в апреле 2020 года первом полном месяце пандемии - что составляет примерно на $30 \%$ больше смертей, чем количество смертей от COVID, зарегистрированных в этом месяце» [10].

По 27 странам Европейского Союза Еurostat оценивает избыточную смертность за март-декабрь 2020 года в 580 тыс. чел.
[11]. Далее эксперты Eurostat сообщают, что «во время первого пика смертности в апреле 2020 года три страны вышли за рамки 50\% превышения смертности: Испания $(+79,4 \%)$, Бельгия $(+73,9 \%)$ и Нидерланды $(+53,6 \%)$. В трех других странах рост смертности в апреле превысил $35 \%$, а именно в Италии $(+41,7 \%$, хотя самый высокий рост уже произошел в марте: $+49,6 \%)$, Швеции $(+38,3 \%)$ и Франции $(+36,4 \%)$. Затем второй резкий рост избыточной смертности появился в большинстве государств-членов, даже в тех, которые не особенно обеспокоены весенними пиками. Увеличение более чем на 10\% по сравнению с исходным уровнем впервые было зарегистрировано в Румынии в июле $(+11,7 \%)$, в Польше в августе $(+11,3 \%)$, а также в Чехии $(+11,4 \%)$ и Греции $(+10,3 \%)$ в сентябре. Начиная с сентября, подъем стал более сильным и универсальным, достигнув новых пиков в ноябре, со значительно высокими темпами в Болгарии $(94,3 \%)$, Польше $(96,9 \%)$, Словении $(88,7 \%)$, Чехии $(75,8 \%)$, Румынии $(63,1 \%)$ и Венгрии $(58,9 \%)$. Среди стран ЕС, которые уже сильно пострадали весной, избыточная смертность все еще была высокой: в ноябре в Бельгии (59,2\%), Италии $(51,6 \%)$, Австрии $(47,8 \%)$, Мальте $(37,9 \%)$, Франции $(31,2 \%)$ и Испании $(27,5 \%)$ [11].

\section{Избыточная смертность в РФ}

В РФ в последние 20 лет происходило достаточно стабильное сокращение показателей общей смертности населения и увеличение ожидаемой продолжительности предстоящей жизни (см. таблицу 1 и рисунок 1). Пандемия COVID-19 переломила эту тенденцию. Общий прирост числа умерших в 2020 году по сравнению с 2019 годом составил 323,8 тыс. чел. Это и есть избыточная смертность за 2020 год. Накопленная избыточная смертность за период с марта 2020 г. по март 2021 г. составляет 588,4 тыс. чел., что на период написания данной статьи может рассматриваться как наиболее полная оценка численности человеческих потерь РФ от пандемии. Как показано в таблице 2, наибольшие потери РФ понесла в марте 2021 года, вследствие накопленного (кумулятивного) эффекта негативных факторов предшествующего периода, хотя к этому времени вторая волна пандемии в нашей стране уже закончилась, а третья только начала подниматься, но с очень низкой интенсивностью, по сравнению с предшествовавшими волнами. 
Таблица 1

Общее число умерших, общий коэффициент смертности, ожидаемая продолжительность предстоящей жизни (лет) в РФ в 2002-2020 гг. (Росстат [8])

\begin{tabular}{|c|c|c|c|}
\hline Годы & $\begin{array}{c}\text { Число умерших, } \\
\text { тыс. чел }\end{array}$ & $\begin{array}{c}\text { Общий коэффициент } \\
\text { смертности, промилле }\end{array}$ & $\begin{array}{c}\text { Ожидаемая продолжительность } \\
\text { предстоящей жизни, лет }\end{array}$ \\
\hline 2002 г. & 2332,3 & 16,2 & 64,95 \\
\hline 2003 г. & 2365,8 & 16,4 & 64,84 \\
\hline 2004 г. & 2295,4 & 15,9 & 65,31 \\
\hline 2005 г. & 2303,9 & 16,1 & 65,37 \\
\hline 2006 г. & 2166,7 & 15,1 & 66,69 \\
\hline 2007 г. & 2080,4 & 14,6 & 67,61 \\
\hline 2008 г. & 2076,0 & 14,5 & 67,99 \\
\hline 2009 г. & 2010,5 & 14,1 & 68,78 \\
\hline 2010 г. & 2028,5 & 14,2 & 68,94 \\
\hline 2011 г. & 1925,7 & 13,5 & 69,83 \\
\hline 2012 г. & 1906,3 & 13,3 & 70,24 \\
\hline 2013 г. & 1871,8 & 13,0 & 70,76 \\
\hline 2014 г. & 1912,3 & 13,1 & 70,93 \\
\hline 2015 г. & 1908,5 & 13,0 & 71,39 \\
\hline 2016 г. & 1891,0 & 12,9 & 71,87 \\
\hline 2017 г. & 1826,1 & 12,4 & 73,00 \\
\hline 2018 г. & 1828,9 & 12,5 & 72,91 \\
\hline 2019 г. & 1800,7 & 12,3 & 73,34 \\
\hline 2020 г. & 2124,5 & 14,5 & 71,50 \\
\hline & & & \\
\hline
\end{tabular}

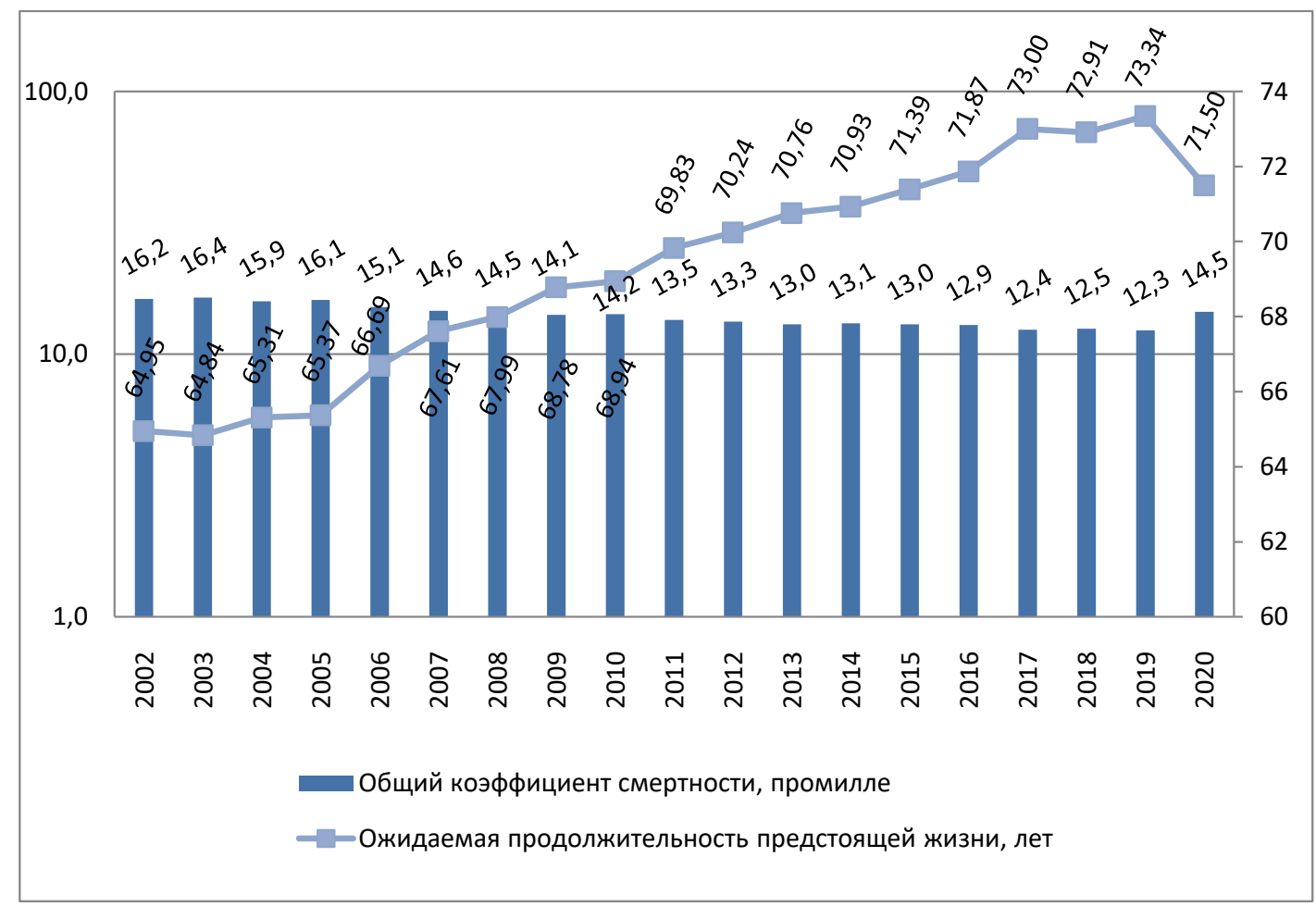

Рис. 1. Общий коэффищиент смертности и ожидаемая продолжительность предстоящей жизни населения РФ в 2002-2021 г2. Источник: Росстат [8] 
Теоретически возможно, что в апреле 2021 года начнется снижение относительных помесячных показателей прироста общего числа умерших за счет того, что вырастет база - показатели соответствующих месяцев 2020 года.

Но в реальной жизни, а не только в ее статистическом отображении, снижение эксцесса смертности начнется тогда, когда произойдут позитивные перемены в заболеваемости COVID-19, в том числе в результате вакцинации населения, которая пока идет недостаточными темпами, и восстановление нормальной работы инфраструктуры здравоохранения, практики оказания плановой медицинской помощи и диспансеризации, ранней диагностики неинфекционных заболеваний.

Обратимся к данным и расчетам, которые представлены в таблице 2. Здесь мы можем показать, чем отличаются широкие показатели смертности от коронавируса Росстата от узких показателей текущей статистики оперативного штаба Правительства РФ, которые в ежедневном режиме публикуются и передаются в ВО3 и другие международные организации. Некоторые эксперты, используя только этот суженный источник данных, и игнорируя Росстат, продвигают тезис о преднамеренном занижении статистики смертности от пандемии в РФ (как и в Китае и некоторых других странах).

Исходя из наблюдения за статистикой и некоторыми актуальными публикациями экспертов различных стран и представителей ВОЗ, мы делаем вывод о чрезвычайном разнообразии в мире национальных практик регистрации смертельных случаев, связанных с коронавирусом, несмотря на наличие общих рекомендаций ВО3.

Таблица 2

Общее число умерших, общий коэффициент смертности, ожидаемая продолжительность предстоящей жизни (лет) в РФ в 2002-2020 гг.

\begin{tabular}{|c|c|c|c|c|c|c|}
\hline & \multicolumn{6}{|c|}{ POCCTAT } \\
\hline & \multicolumn{3}{|c|}{ Основная причина смерти } & \multicolumn{3}{|c|}{$\begin{array}{c}\text { Причина смерти отнесена } \\
\text { к прочим важным состояниям }\end{array}$} \\
\hline & & \multicolumn{2}{|c|}{ в том числе: } & & \multicolumn{2}{|c|}{ в том числе: } \\
\hline & Всего & $\begin{array}{c}\text { COVID-19, } \\
\text { вирус } \\
\text { идентифи- } \\
\text { цирован }\end{array}$ & $\begin{array}{c}\text { возможно, } \\
\text { COVID-19, } \\
\text { вирус не } \\
\text { идентифи- } \\
\text { цирован }\end{array}$ & Всего & $\begin{array}{c}\text { COVID-19 } \\
\text { не является } \\
\text { основной причиной } \\
\text { смерти, но оказал } \\
\text { существенное } \\
\text { влияние на развитие } \\
\text { смертельных } \\
\text { осложнений } \\
\text { заболевания }\end{array}$ & $\begin{array}{c}\text { COVID-19 } \\
\text { не является } \\
\text { основной причиной } \\
\text { смерти и не оказал } \\
\text { существенного } \\
\text { влияния на развитие } \\
\text { смертельных } \\
\text { осложнений } \\
\text { заболевания }\end{array}$ \\
\hline & 1 & 2 & 3 & 4 & 5 & 6 \\
\hline 2020 год & 104826 & 87530 & 17296 & 58499 & 13964 & 44535 \\
\hline апрель & 1748 & 1350 & 398 & 1077 & 435 & 642 \\
\hline май & 7603 & 5926 & 1677 & 5066 & 1609 & 3457 \\
\hline июнь & 7317 & 5825 & 1492 & 5018 & 1484 & 3534 \\
\hline июль & 6084 & 5063 & 1021 & 4287 & 1237 & 3050 \\
\hline август & 4018 & 3436 & 582 & 3655 & 1184 & 2471 \\
\hline сентябрь & 5438 & 4579 & 859 & 4741 & 1428 & 3313 \\
\hline октябрь & 15103 & 13077 & 2026 & 9230 & 1794 & 7436 \\
\hline ноябрь & 25107 & 21262 & 3845 & 12502 & 2288 & 10214 \\
\hline декабрь & 32408 & 27012 & 5396 & 12923 & 2505 & 10418 \\
\hline \multicolumn{7}{|l|}{2021 год } \\
\hline январь & 27455 & 22747 & 4708 & 10423 & 2337 & 8086 \\
\hline февраль & 16576 & 14171 & 2405 & 7793 & 1954 & 5839 \\
\hline март & 17457 & 15003 & 2454 & 6258 & 1401 & 4857 \\
\hline
\end{tabular}


Продолжение табл. 2

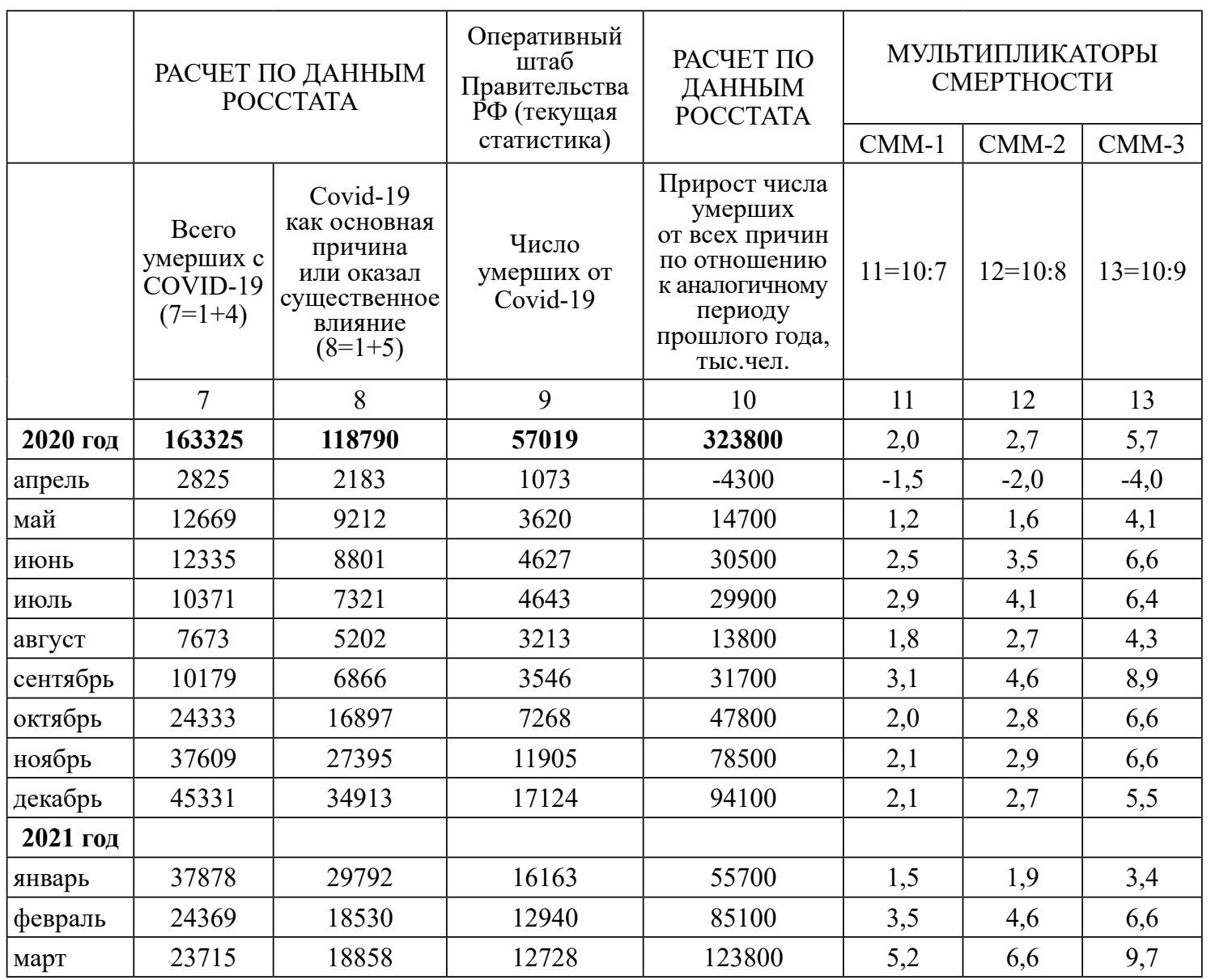

Источник: Росстат [8], расчеты автора

В одних странах все умершие после положительного теста на коронавирус, или просто при наличии симптомов простудных заболеваний, записываются как погибшие от COVID-19. В этих странах практически «исчез грипп» и сократилась смертность от сердечно-сосудистых и других болезней, так как все было списано на коронавирус.

В других странах ежедневная оперативная статистика носит регламентированный характер, и включает только самые явные случаи смерти от коронавируса, как в РФ (как правило после одного или нескольких положительных ПЦР-тестов). В целом за 2020 г. в РФ таких случаев зарегистрировано 57 тысяч. Впоследствии по таким случаям уполномоченными органами здравоохранения производится углубленный анализ причин смерти и в официальной статистике уже выделяются группы причин, согласованные с рекомендациями BO3. В регистрационной практике рос- сийских ЗАГСов и Росстата это категории, показанные в столбцах 1-6 таблицы 2. Это случаи, в которых коронавирус является главной причиной смерти - 104,8 тысячи за 2020 год (из них 87,5 тыс. случаев, когда вирус был идентифицирован). Из сопоставления соответствующих цифр мы уже видим, что эта категория значительно шире, чем данные оперативной статистики. Но дальше мы видим за 2020 год еще 58,5 тысяч случаев, в которых люди умерли при наличии коронавируса, но от других заболеваний. Таким образом широкая оценка смертности, связанной с COVID-19 в РФ за 2020 год составляет 163,3 тыс. чел., а за период до марта 2021 года включительно - 249,3 тыс. чел. И таким образом, смертность, связанная с коронавирусом, составляет не несколько процентов, а около половины от показателя всей дополнительной (избыточной) смертности в РФ за период пандемии. 


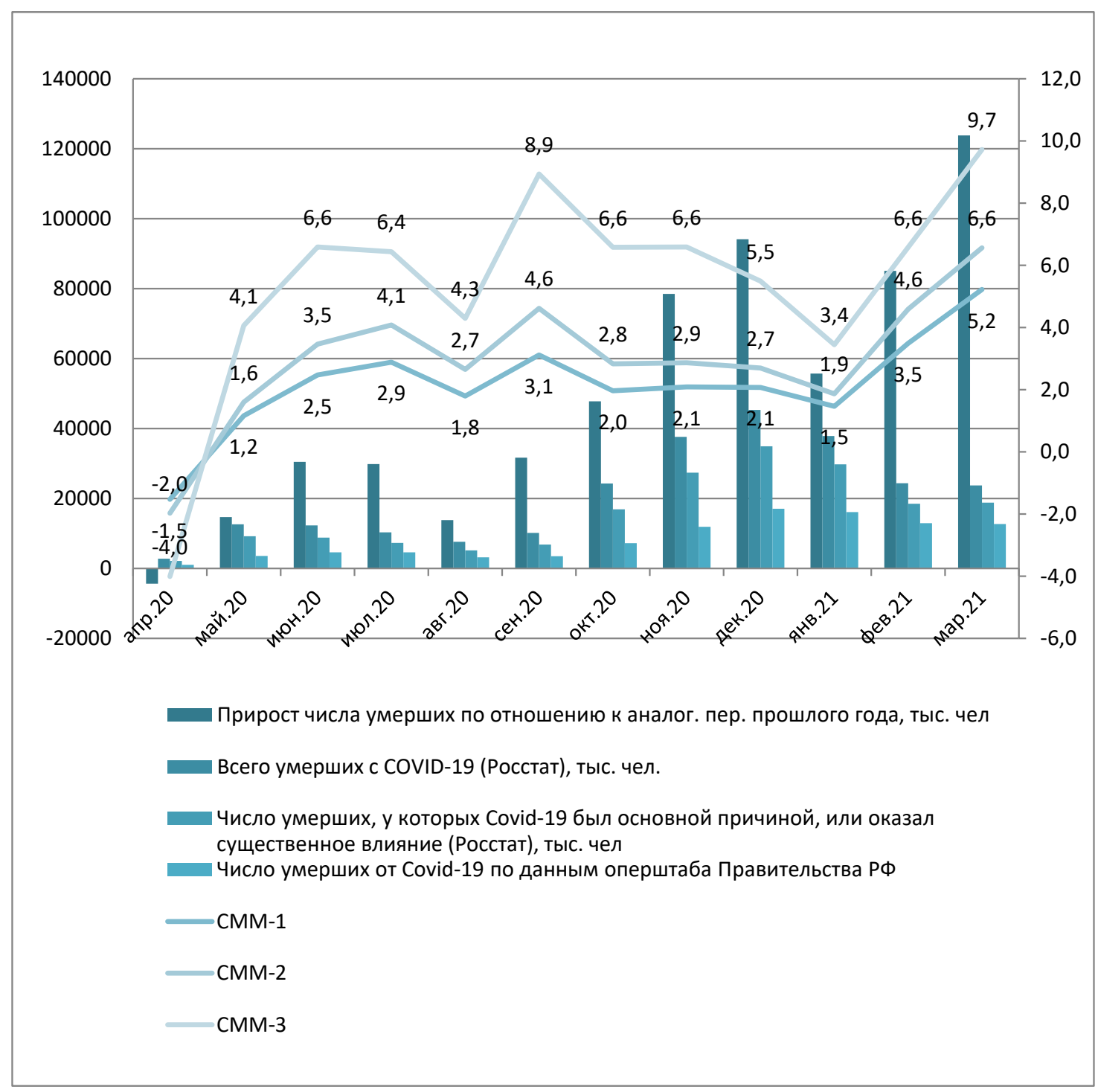

Puc. 2. Числа умерших от всего причин, от COVID-19 и коэффициенты CMM по месячам 2020-2021 г2. Источник: Росстат [8], расчеты автора

На наш взгляд, это снимает вопросы о преднамеренном занижении соответствующих данных по коронавирусу, но оставляет актуальной для дальнейшего обсуждения проблему готовности российской системы здравоохранения к пандемии после ранее произведенной «оптимизации».

\section{Заключение}

Предложенная нами методология СММ реализована в расчетах, показанных в таблице 2 и на рисунке 2 , простым и понятным образом - три рассчитанных коэффициента различаются широтой показателя смертности, связанной с COVID-19, то есть оценкой знаменателя $\mathrm{M}_{\mathrm{c}}$ в формуле
1. В СММ-3 самый узкий знаменатель оперативная ежедневная статистика, поэтому коэффициент самый значительный, в СММ-2 знаменатель содержит, согласно итоговым расчетам Росстата, случаи смерти в которых коронавирус выступает как основная причина смерти, или оказал существенное влияние, и в СММ-1 включены все случаи умерших при наличии COVID-19, что соответствует реальной практике многих развитых стран мира. Тем не менее наши расчеты показывают примерное соответствие колебаний всех трех коэффициентов СММ прохождению первых двух волн пандемии и их резкий рост в марте 2021 года. 
Библиографический список

1. Кашепов А.В. Прогнозирование конъюнктуры рынка труда в условиях современных институциональных реформ // Социально-трудовые исследования. 2019. №1. С. 44-56.

2. Кашепов А.В. Социально-экономические факторы смертности в период с 2000 по 2020 гг. // Социально-трудовые исследования. 2020. № 40 (3). С. 18-30.

3. Кашепов А.В. Институциональные и экономические проблемы здравоохранения в России // Вестник Алтайской академии экономики и права. 2020. № 11-2. С. 244-253.

4. Johns Hopkins university. Coronavirus resource center. URL: https://coronavirus.jhu.edu/map.html.

5. United Nations, Department of Economic and Social Affairs, Population Division (2019). World Mortality Report 2019, CD-ROM Edition - Datasets in Excel formats (POP/DB/MORT/2019). URL: https://www.un.org/ en/development/desa/population/publications/mortality/world-mortality-cdrom-2019.asp.

6. Ракша А. Неизвестные смерти: что скрывается за коронавирусной статистикой. Forbes. 18.05.2020. URL: https://www.forbes.ru/obshchestvo/400729-neizvestnye-smerti-chto-skryvaetsya-za-koronavirusnoy-statistikoy.

7. Щербакова Е.M. Старение населения мира - взгляд из 2020 года // Демоскоп Weekly. 2020. № 879-880. URL: http://demoscope.ru/weekly/2020/0877/barom01.php.

8. Официальный сайт Федеральной службы государственной статистики (Росстата). URL: https:// rosstat.gov.ru.

9. United States Census Bureau. URL: https://www.census.gov/en.html.

10. Udalova V. Racial Inequality in Pandemic Mortality Widens When Age, Indirect Impact Taken Into Account. URL: https://www.census.gov/library/stories/2021/02/indirect-impact-of-covid-19-results-in-higherpandemic-death-toll.html.

11. Eurostat. 580000 excess deaths between March and December 2020. URL: https://ec.europa.eu/eurostat/ en/web/products-eurostat-news/-/ddn-20210312-2. 